Proceedings of

the $35^{\text {th }}$ International Business Information Management Association Conference

(IBIMA)

1-2 April 2020

Seville, Spain

ISBN: 978-0-9998551-4-1

Education Excellence and Innovation Management:

A 2025 Vision to Sustain Economic Development during Global Challenges

Editor

Khalid S. Soliman

International Business Information Management Association (IBIMA)

Copyright 2020 


\title{
Organizational Justice and Performance Among Academic Staff
}

\author{
Alaa S. Jameel \\ Faculty of Technology Management and Business, Universiti Tun Hussein Onn Malaysia 86400 Batu \\ Pahat, Johor, Malaysia \\ salam.alaa23@gmail.com \\ Abd Rahman Ahmad \\ Faculty of Technology Management and Business, Universiti Tun Hussein Onn Malaysia 86400 Batu \\ Pahat, Johor, Malaysia \\ arahman@uthm.edu.my \\ Mohammed A. Karem \\ Department of Public Administration, Cihan University-Erbil, Kurdistan Region, Iraq \\ mohammad.abdulkarem@cihanuniversity.edu.iq
}

\begin{abstract}
Job performance is one of the most critical topics in literature. Additionally, both managers and researchers paid more attention to this topic due to a crucial role in the success of organizations. There is a limited study conducted in developing countries. Likewise, most of the previous studies focused on organizations and limited studies conducted in the education field. This paper develops a conceptual model for organizational Justice and job performance to fill this gap. The potential participants of this study were academic staff at Iraqi public universities selected depending on stratified sample technic from 9 universities located in Baghdad. Based on the finding of previous studies, the results suggest that organizational justice dimensions are one of the most important factors that influence organizational performance.
\end{abstract}

Keywords: Job performance, organizational Justice, academic staff, university Rank, Higher education.

\section{Introduction}

Job performance (JP) consider one of the most crucial topics in the literature. It is primary interest to both managers and researchers, Due to its vital role in the success of organizations. Therefore, necessary to understand the mechanisms that affect job performance, particularly among academic staff. Besides, university performance is primarily determined by academic staff activities such as publications, conferences, patents and community service. This study attempts to add to the literature by offering a more detailed understanding of how organizational justice (OJ) influences job performance. Many factors affecting the performance of an employee are studied, while limited studies have examined the effect of OJ on JP among academic staff. Meanwhile, organizational Justice, a neglecting topic in higher education institutions. Most of the previous studies paid more attention to find the impact on performance appraisal (Byrne et al., 2012; Tinuke, 2015; Onuselogu and Adaobi P., 2017) and limited studies have been conducted to find the impact of OJ on JP in the educational field (Arab and Atan, 2018). Meanwhile, the procedural Justice has been selected as the primary indicator of job performance in most of the studies (J. A.Colquitt, 2001; Zapata-Phelan et al., 2009; Chien, Lawler and Uen, 2010; Suliman and Kathairi, 2013), While there are other two dimensions of OJ which neglected by the most of previous studies, particularly in the higher education context.

Iraqi universities suffering from low ranking among regional universities (Webometric, 2020) Furthermore, university ranking highly depend on academic staff performance in term of Research productivity (Mousa, Jameel and Ahmad, 2019; Jameel and Ahmad, 2020). The number of publications 
for Iraqi universities in a reliable database is only 28091 (SJR, 2020) this number placed the Iraqi universities in low rank.

Purpose of this study is to propose the conceptual framework that may examine in higher education institutes, particularly in Iraqi universities in future studies.

\section{Literature Review}

\section{Academic Performance}

The term of academic is usually used about the school, university, or any higher-learning institution. This involves human academic activities in a structured educational environment. While, Performance is an activity, implementation and production. Performance refers to as what is accomplished under current circumstances which subsume the mechanism of obtaining and using knowledge skills structure and a host of successful, motivational and stylistic factors influencing the ultimate responses (Karem et al., 2019; Jameel and Ahmad, 2020). (Armstrong 2010) Defined Performance as achievement, implementation, success, the efficiency of anything done, and contributing to outputs/outcomes (accomplishment). (Jameel and Ahmad, 2019a) and (Karem et al., 2019) Indicate that performance is the execution of specific tasks calculated against specified reliability, completeness, cost and requirements. (Jameel and Ahmad, 2020) and (Jameel and Ahmad, 2020) emphasize were that education, research/publication and community service positions were essential for the growth of any nation internationally since these roles specifically promote social welfare, financial literacy, safety and reduced crime in communities. Research is one of the reasons why universities were founded, leading to new information development, the production of technology, enhanced service quality and increased educational prestige and economic value. The performance of universities mostly measures by the efforts of academic and non-academic staff. Academic staff at university comprise people who carry out educational work at the university, including teaching, research, and, in some instances, administrations. However, Educational achievements are the primary criteria used to assess university academic performance (Jameel and Ahmad, 2019a, 2019b). According to Tinuke (2015); Abba and Mugizi (2018) the criteria which could measure the academic performance such as staff skills, material resources, teaching, publication, research and community service.

\section{Organizational Justice}

Throughout recent years, social justice study has attracted significant interest. Studying Justice in psychology began with Adams ' monograph on equity theory (Adams, 1963) stressing assumed fairness in performance. Nevertheless, considering the importance researchers assign to justice existence, reproducing and expanding this research area was unavoidable. Organizational Justice may clarify a wide range of workplace attitudes, highlighting the importance of equality and equity values as a prerequisite for organizations to function effectively. However, (Greenberg, 2004) believe that OJ can decrease job stress. However, According to Lee et al., (2015); Karem, Jameel and Ahmad (2019) Justice is a vital element in the development and maintenance of a sustainable labour environment defined as a Member's sense of the moral property of the way they are treated. OJ is the understanding of the equity with which an entity handles workers (Greenberg, 2004). OJ can be defined as a quality of mutual interest, affecting both interactions with others and consequences that influence the physical, psychological and social health of others (Cropanzano et al., 2001; Jameel, Mahmood and Jwmaa, 2020). OJ often has three components: Distributive Justice (DJ), Procedural Justice (PJ) and Interactional Justice (IJ) (Leventhal, 1980; Bies and Moag, 1986).

\section{Distributive Justice}

DJ includes the allocation of incentives for work related to outputs. It is based on the theory of equity, in which expectations of unequal distribution of job incentives compared to work contributions could create tension among the employees. Likewise, Distributive fairness is the degree to which the 
institutions' individuals view the distribution of resources (Greenberg, 1990; Jameel, Mahmood and Jwmaa, 2020). DJ relates to the Justice of particular results relative to that obtained by others (Farndale, Hope-Hailey and Kelliher, 2011; Karem, Jameel and Ahmad, 2019). DJ primarily applies to the organization's performance.

\section{Procedural Justice}

The degree to which uniformity occurs in the decision-making process of an institutions' and to what extent the views of representatives are expressed in the decision-making process is known as PJ (Greenberg, 1990). PJ applies to whether decision-making procedures maintain continuity and whether beneficiaries of these judgments can affect the system (Byrne et al., 2012). The procedural Justice refers to facets of corporate transition processes. Furthermore, PJ represents the formal expectations and performance of the communication partnerships in the decision-making process; $\mathrm{PJ}$ is distinct from IJ as it illustrates the informal connections between the decision-making unit and the approving institution (Karem, Jameel and Ahmad, 2019; Yu et al., 2019).

\section{Interactional Justice}

IJ characterized as the degree of treatment obtained by institution participants like provide details to them, especially when the making decision (Yu et al., 2019) and (Karem, Jameel and Ahmad, 2019). Interactional Justice addresses the association between workers and the institution and the treatment of individuals (Jameel, Mahmood and Jwmaa, 2020). However, Interactional Justice, often perceived an element of PJ, refers to how one is handled during the execution of a system or policy (e.g. with respect and dignity) and stresses the interaction and social process dimensions (Bies and Moag, 1986).

\section{Proposed Model and Propositions}

Based on the literature, this study proposes that organizational Justice will affect positively on job performance among academic staff. Figure 1 illustrates the conceptual framework

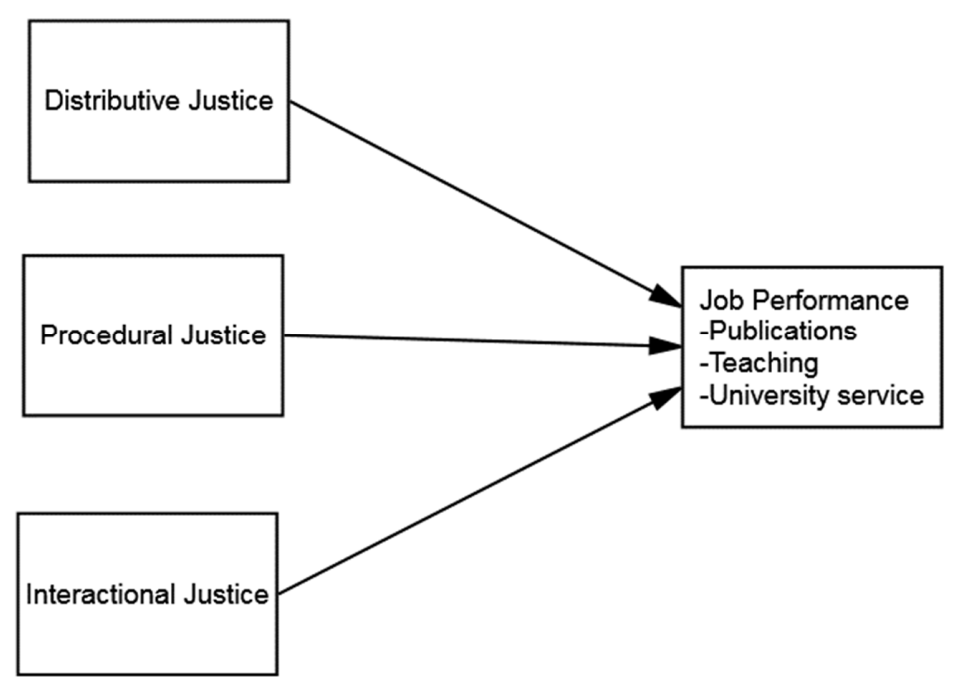

Figure 1 : conceptual framework 


\section{Hypotheses development}

\section{Organizational Justice and Job Performance}

The universities are the only organizations centred on dual-core functions of information development and dissemination through research, teaching and community engagement processes (Jameel and Ahmad, 2020). Although university academic staff do intricate work in an increasingly tricky setting, both in the area of teaching and research. Several researchers indicated that performance and engagement at work were two significant findings related to the sense of Justice (J. A.Colquitt, 2001; Cropanzano, Bowen and Gilliland, 2007; Zapata-Phelan et al., 2009).

When individuals agree social and mental requirements such as speech, respect and dignity (dimensions of PJ and IJ) are fairly treated, they will generally Respond to higher performance and feel stronger. If organizations develop high-quality communication agreements with their workers by handling them equally and allowing them to make decisions about their results (fair processes), employees are more fulfilled and more likely to work to achieve a better standard of JP. Individuals are expected to show enough work performance and feel dissatisfied if they assume, they are low exchange relation. Empirical studies have demonstrated usually that DJ significantly predicted to Job performance (J. A.Colquitt, 2001; Shan, Ishaq and Shaheen, 2006; Cropanzano, Bowen and Gilliland, 2007). However, many findings have shown that PJ leads actively and substantially impact on JP (J. A.Colquitt, 2001; Shan, Ishaq and Shaheen, 2006; Zapata-Phelan et al., 2009; Chien, Lawler and Uen, 2010; Suliman and Kathairi, 2013). However, IJ relation to JP remains unclear, and correlation experiments between these two factors produced mixed results, Some studies reported the IJ was not related and does not impact on job performance (Colquitt et al., 2006; Zapata-Phelan et al., 2009). While some other studies found a significant positive relationship (Shan, Ishaq and Shaheen, 2006; Suliman and Kathairi, 2013). According to the above mentioned, the study proposes the following hypotheses.

Proposition 1: Distributive Justice has a significant and positive effect on Job Performance among academic staff. Proposition 2: Procedural Justice has a significant and positive effect on Job Performance among academic staff. Proposition 3: Interactional Justice has a significant and positive effect on Job Performance among academic staff.

\section{Research Methodology}

In general, several conceptual frameworks on organizational Justice and job quality are available.

\section{Measurement}

This describes the four variables briefly to be used in the models. First, the distributive justice measures were drawn from a previous study that assessed the employee's perception of equality and equity, Items propose to adapted from (Leventhal, 1980) to assess academics staff perceiving distributive Justice. Second Procedural Justice shall be specified as necessary in the assignment process, such as coherence, lack of bias, reliability, equality of the applicants, correction and ethics of the organizational procedures Items propose to adapted from (Leventhal, 1980). The third factor incorporates the Items propose to adapted from (Bies and Moag, 1986), which analyzed the appropriateness of care workers to interactional Justice obtained from an individual of authority. Fourth Job performance Items propose to adapted from (Shan, Ishaq and Shaheen, 2006; Musah et al., 2016; Abba and Mugizi, 2018) to measure the academic staff performance in term of publications, Teaching and university services. 


\section{Unit of Analysis}

The potential participants were academic staff at Iraqi public universities selected depending on stratified sample technic from 9 universities located in Baghdad.

\section{Statistical Data Analysis}

To achieve the study aims, the Structural Equation Model (SEM), particularly, an analysis of a moment structures (AMOS) appropriate because the techniques allow multiple equations to be simultaneously calculated and conduct a variable analysis, including path analysis in one stage (Hair et al., 2014). The study should be carried out in two phases. First, based on the confirmatory factor analysis, the measurement framework is estimated. Second, researchers examine the conceptual model and measure the path coefficients (Hair et al., 2014).

\section{Expected Findings}

The researchers expect to find there is a strong impact of Organizational Justice dimensions on Job performance among the academic staff. It is also likely that the study will reveal that a favourable situation with regards to the Organizational Justice dimensions mentioned will also lead to a more positive Job performance. These findings are in accordance with other studies completed in the past, such as that of (J. A.Colquitt, 2001; Shan, Ishaq and Shaheen, 2006; Cropanzano, Bowen and Gilliland, 2007), which have all found the positive prediction of organizational Justice on job performance.

\section{Conclusion}

This paper proposed that Organizational Justice could be the most critical factor to predict job performance. Furthermore, academic staff performance plays a vital role in enhancing the universities ranking, community services and teaching quality. In this context, we proposed in this study the conceptual framework to determinants organizational justice and academic performance. Research in developing countries are still behind the developed countries, and the grading and quality of education in the universities of developing countries need to be improved. This study was designed specifically for testing in a developing country. The authors will, in future empirically examine the proposed model by deploying an academic population at both private andlor public universities. Stratified samples or random sample data may be collected through a questionnaire.

\section{References}

- Abba, H. D. and Mugizi, W. (2018) 'Performance of academic staff in polytechnics: an analysis of performance levels in North West geo-political zone of Nigeria', Arts \& Humanities Open Access Journal, 2(3). doi: 10.15406/ahoaj.2018.02.00056.

- Adams, J. S. (1963) 'Towards an understanding of inequity', Journal of Abnormal and Social Psychology, 67(5), pp. 422-436. doi: 10.1037/h0040968.

- Arab, H. R. and Atan, T. (2018) 'Organizational justice and work outcomes in the Kurdistan Region of Iraq', Management Decision, 56(4), pp. 808-827. doi: 10.1108/MD-04-2017-0405.

- Bies, R. J. and Moag, J. S. (1986) 'Interactional justice: communication criteria of fairness', in Research in negotiations in organizations. Greenwich: JAI Press, pp. 43-55. doi: 10.1111/j.15591816.2004.tb02581.x.

- Byrne, Z. S. et al. (2012) 'Trusting the fair supervisor: The role of supervisory support in performance appraisals', Human Resource Management Journal, 22(2), pp. 129-147. doi: 10.1111/j.1748-8583.2012.00193.x.

- Chien, M. S., Lawler, J. S. and Uen, J. F. (2010) 'Performance-based pay, procedural justice and job performance for R\&D professionals: Evidence from the taiwanese high-tech sector', International Journal of Human Resource Management, 21(12), pp. 2234-2248. doi: 
$10.1080 / 09585192.2010 .509626$.

- Colquitt, J. A. et al. (2006) 'Justice and personality: Using integrative theories to derive moderators of justice effects', Organizational Behavior and Human Decision Processes, 100(1), pp. 110-127. doi: 10.1016/j.obhdp.2005.09.001.

- Cropanzano, R. et al. (2001) Three roads to organizational justice, Research in Personnel and Human Resources Management. New York, NY: Elsevier Science. doi: 10.1016/S07427301(01)20001-2.

- Cropanzano, R., Bowen, D. E. and Gilliland, S. W. (2007) 'The management of organizational justice', Academy of Management Perspectives, 21(4), pp. 34-48. doi: 10.5465/AMP.2007.27895338.

- Farndale, E., Hope-Hailey, V. and Kelliher, C. (2011) 'High commitment performance management: The roles of justice and trust', Personnel Review, 40(1), pp. 5-23. doi: $10.1108 / 00483481111095492$.

- Greenberg, J. (1990) 'Organizational Justice: Yesterday, Today, and Tomorrow', Journal of Management, 16(2), pp. 399-432. doi: 10.1177/014920639001600208.

- Greenberg, J. (2004) 'Stress fairness to fare no stress: Managing workplace stress by promoting organizational justice', Organizational Dynamics, 33(4 SPEC.ISS.), pp. 352-365. doi: 10.1016/j.orgdyn.2004.09.003.

- Hair, J. F. et al. (2014) 'Partial least squares structural equation modeling with R', Practical Assessment, Research and Evaluation, 21(1), pp. 1-16. doi: 10.1108/ebr-10-2013-0128.

- Igbojekwe, P. and Ugo-Okoro, C. P. (2015) 'Performance Evaluation of Academic Staff in Universities and Colleges In Nigeria : The Missing Criteria .', International Journal of Education and Research, 3(3), pp. 627-640.

- J. A.Colquitt (2001) 'On the dimensionality of organizational justice: A construct validation of a measure', Journal of applied psychology, 68(3), pp. 386-399.

- Jameel, A. S. and Ahmad, A. R. (2019a) 'Leadership and Performance of Academic Staff in Developing Countries', in the 33rd International Business Information Management Association Conference. Granada, Spain: IBIMA, pp. 6101-6106.

- Jameel, A. S. and Ahmad, A. R. (2019b) 'The effect of Transformational Leadership on Job Satisfaction among Academic Staff', in In The 34th International Business Information Management Association (IBIMA) conference: 13-14 November 2019, Madrid, Spain.

- Jameel, A. S. and Ahmad, A. R. (2020) 'The Mediating Role of Job Satisfaction between Leadership Style and Performance of Academic Staff', International Journal of Psychosocial Rehabilitation, 24(04), pp. 2399-2414. doi: 10.37200/IJPR/V24I4/PR201349.

- Jameel, A. S., Mahmood, Y. N. and Jwmaa, S. J. (2020) 'Organizational Justice and Organizational Commitment among Secondary School teachers', Cihan University-Erbil Journal of Humanities and Social Sciences, 4(1), pp. 1-6. doi: 10.24086/cuejhss.vol4n1y2020.pp1-7.

- Karem, M. A. et al. (2019) 'The Effect of Job Satisfaction and Organizational Commitment on Nurses' Performance', Humanities and Social Sciences Reviews, 7(6), pp. 332-339. doi: 10.18510/hssr.2019.7658.

- Karem, M. A., Jameel, A. S. and Ahmad, A. R. (2019) 'The Impact of Organizational Justice Dimensions on Organizational Commitment among Bank Employees', International Journal of Psychosocial Rehabilitation, 23(02), pp. 502-513.

- Lee, Y. K. et al. (2015) 'Linking Organizational Justice to Job Performance: Evidence from the Restaurant Industry in East Asia', Asia Pacific Journal of Tourism Research, 20(June), pp. 15271544. doi: 10.1080/10941665.2015.1016052.

- Leventhal, G. S. (1980) 'What should be done with equity theory? New approaches to the study of fairness in social relationships', in Social exchange: Advances in theory and research.

- Mousa, T. S., Jameel, A. S. and Ahmad, A. R. (2019) 'The Impact of Attitude, Subjective Norm and Information Communications Technology on Knowledge Sharing among Academic Staff', International Journal of Psychosocial Rehabilitation, 23(02), pp. 704-717.

- Musah, M. B. et al. (2016) 'Organisational climate as a predictor of workforce performance in the Malaysian higher education institutions', Quality Assurance in Education, 24(3), pp. 416-438. doi: 10.1108/QAE-10-2014-0048.

- Onuselogu and Adaobi P. (2017) 'Effect of academic staff promotional appraisal measures on 
academic performance of universities in anambra state', Online Journal of Arts, Management and Social Sciences, 2(3), pp. 64-73.

- Shan, S., Ishaq, H. M. and Shaheen, M. A. (2006) 'Impact of organizational justice on job performance in libraries Mediating role of leader-member exchange relationship', Library Management, 36((112)), pp. 70-85.

- SJR (2020) Scimago Journal and Country Rank, Scimago Journal and Country Rank. Available at: https://www.scimagojr.com/countryrank.php?region=Middle East.

- Suliman, A. and Kathairi, M. Al (2013) 'Organizational justice, commitment and performance in developing countries: The case of the UAE', Employee Relations, 35(1), pp. 98-115. doi: $10.1108 / 01425451311279438$.

- Tinuke, F. M. (2015) 'Dimensions of University Academic Staff Performance Appraisal in Selected Public Universities in Nigeria', Journal of Global Economics Management and Business Research, 3(3), pp. 139-147.

- Webometric (2020) Webometric ranking of world universities, Webometric Website. Available at: http://www.webometrics.info/en/Asia_Pacifico/Middle_East.

- Yu, J. et al. (2019) 'Organizational Justice and Performance of Hotel enterprises: Impact of Job Embeddedness', Journal of Quality Assurance in Hospitality \& Tourism, DOI:, pp. 1-24.

- Zapata-Phelan, C. P. et al. (2009) 'Procedural justice, interactional justice, and task performance: The mediating role of intrinsic motivation', Organizational Behavior and Human Decision Processes, 108(1), pp. 93-105. doi: 10.1016/j.obhdp.2008.08.001. 